\title{
Does Culture Make a Better Citizen? Exploring the Relationship Between Cultural and Civic Participation in Italy
}

\author{
Desirée Campagna $^{1}$ (D) - Giulio Caperna ${ }^{2}$ D $\cdot$ Valentina Montalto ${ }^{2}$ (D)
}

Accepted: 2 January 2020 / Published online: 31 January 2020

(c) The Author(s) 2020

\begin{abstract}
In the last decades, policy discussions have increasingly considered participation in arts and cultural activities as a vehicle to reach broader social policy goals, such as social inclusion or active citizenship. However, convincing empirical evidence on the social impacts of arts and culture is still scarce. In particular, little attention has been given to the impact that cultural participation may have on individuals' engagement in civil society, especially in Europe. In order to address this lack of evidence, this paper explores the connection between cultural participation and civic participation in Italy using Likert-scale data collected in the ISTAT “Aspetti della Vita Quotidiana” Survey (2014). To do so, two composite indicators - the participation in cultural life indicator and the participation in civic life indicator-have been built using an approach based on partial order theory and the concept of Average Rank. The effect of cultural participation on civic engagement has been estimated using a quantile regression model which controls for potentially cofounding factors such as education, income, age and gender. Results do confirm that participation in arts and cultural activities is highly correlated with participation in civic life. It is particularly worth noticing that at higher levels of civic participation, cultural participation has a positive and strong effect on civic engagement of people having a low educational level.
\end{abstract}

Keywords Cultural participation · Civic engagement $\cdot$ Composite indicators $\cdot$ Poset theory $\cdot$ Social impacts

\section{Introduction}

The role that participation in arts and cultural activities can play in the achievement of broader social policy goals, such as countering social exclusion or promoting active citizenship, is increasingly addressed in the international cultural policy debate. The European

Giulio Caperna

giulio.caperna@ec.europa.eu

1 University Human Rights Centre, University of Padova, Via Martiri della Libertà, 2, 35137 Padua, Italy

2 Joint Research Centre of the European Commission, Via E. Fermi, 2749, 21027 Ispra, VA, Italy 
Union, in particular, has progressively referred to the cultural dimension of social inclusion and the potential of cultural participation to tackle exclusion (e.g. Council of the European Union 2010; European Commission 2007, 2013, 2017a, 2018; European Commission and Council of the European Union 2004; European Parliament 2002, 2007) being the "social dimension" at the core of the European Union project (European Commission 2017b). At national level, various European countries such as Cyprus, Sweden, Switzerland, France, Italy, the Netherlands and UK (Kononykhina et al. 2016) have recognized and promoted the contribution of culture to social inclusion.

The essay "Use or Ornament?" (Matarasso 1997) was probably one of the most influential reports in advocating for the transformative power of arts participation as a means for producing beneficial effects both at individual and community level. Referring to 60 cultural projects promoted in UK and through a survey conducted by a questionnaire submitted to 513 participants, Matarasso argued that not only arts and culture contribute to skills building and educational growth but that they are also positively related with social cohesion and community development, making individuals more willing and capable of actively engaging in society. On the one hand, this argument had great influence on both cultural policy makers and cultural organisations. It indeed contributed to show to governments new ways of approaching difficult social issues (e.g. poverty, social exclusion, health, etc.) and helped cultural operators advocate for public funds, giving rise to a growing "rhetoric of instrumentalism" about cultural participation (Belfiore 2006). On the other hand, however, the lack of robust empirical evidence strongly puts in discussion the social impacts of culture [see the extensive literature reviews conducted by Jeannotte (2017) and McCarthy et al. (2004)], making such impacts more a myth based on anecdotal declarations than a reality, according to some scholars (e.g. Merli 2002). Existing data are mostly drawn from case studies, project evaluations, cameos, briefs on the engagement with specific groups in the community, and quotations from staff or project participants (Selwood 2002). This is not usually sufficient to demonstrate specific associations, effects, or causality and may be (positively) misleading.

In order to address this "evidence dilemma", we have explored one specific aspect of the social impact of participation in cultural activities, namely the effect of the cultural participation rate, i.e. frequency of engagement for an individual in a wide range of cultural activities, on civic engagement, i.e. the behaviours and actions that an individual accomplishes to give a positive contribution to the life in the community. In other words, we have tried to examine the contribution of cultural participation to the "relational dimension" of social inclusion typical of the French approach and which complements the "economic dimension" (e.g. access to employment opportunities) emphasised by the Anglo-American one (e.g. Atkinson et al. 2002).

Only a few studies have specifically focused on the link between cultural and civic participation (e.g. Catterall et al. 2012; Delaney and Keaney 2006; Hill 2008; Jeannotte 2003; Leroux and Bernadska 2014; National Endowment for the Arts (NEA) 2009; Polzella and Forbis 2016; Stern and Seifert 2009), often finding a positive correlation between at least some forms of cultural participation (e.g. attending music concerts) and civic engagement variables such as volunteering, donating or interpersonal trust. These studies, however, cannot explain the causal mechanisms that connect participation in cultural and civic life due to the difficulty of disentangling such complex, multi-faceted and often "nested" phenomena. Previous works rarely consider the broad spectrum of cultural and civil society activities that individuals can engage with due to data limitations, and mostly focus on the US, using data for one single point in time while cultural participation effects are likely to be produced and observed across time. 
Our paper seeks to remedy some of these gaps. Two composite indicators-participation in cultural life indicator (PCULT) and the participation in civic life indicator (PCIVIC) were built with a view to capture the multidimensional concepts of interest with the help of the theory of Partially Ordered Sets (poset theory) and using the concept of Average Rank (AR) that better fits the ordinal nature of the used data as opposed to other commonly used aggregation methods (e.g. arithmetic averages). Italy was chosen as a "test-case" due to the availability of very much relevant data coming from the survey "Aspetti della Vita Quotidiana (AVQ)" (ISTAT 2014), which gave us the opportunity to consider many diverse kinds of cultural participation activities, ranging from museum attendance to "active" arts practice such as playing an instrument, for a cross-sectional type of analysis. A quantile regression model was used to assess the relation of cultural participation with engagement in civic life. Although this model does not allow us to fully assess the existence of a causal relationship, it has the advantage of isolating the effect that potentially cofounding variables, such as income, education and age, may have on cultural participation and civic engagement. The inclusion in the model of interaction terms linking cultural participation with socio-demographic variables provides deeper insights on the relations between the two constructs under investigation.

The structure of this paper is as follows. Firstly, an operational definition of both cultural participation and civic engagement is provided, shedding light on the different dimensions and sub-dimensions of each concept in line with the extant literature on the topic. Secondly, the selection and treatment of variables from the ISTAT AVQ Survey (2014) is explained, showing how the selected variables are able to empirically measure the two concepts and what adjustments were made and why. Thirdly, the construction of the synthetic indicators-PCULT and PCIVIC - is illustrated. Finally, the results concerning the relationship between the two indicators are presented and discussed, underlying the possible policy implications of our findings and proposals for future research.

\section{Defining Cultural Participation and Civic Engagement}

Both cultural participation and civic engagement are multi-dimensional concepts that involve a broad range of cultural, social and political activities that could be carried on both at individual and a community level. Taking into consideration this intrinsic complexity, on the one hand, and data currently available in Italy, on the other, this paper does not intend to propose new theoretical definitions but rather offers two operational frames for both cultural participation and civic engagement with a view to make the two concepts measurable and empirically explore their relation.

\subsection{Participation in Cultural Life}

Cultural participation is hard to define as it has to refer, on the one hand, to the concept of "culture" and, on the other, to that of "participation" that can go from the attendance at formal events to informal cultural practices that are knitted into the fabric of everyday life. Today, the definition also has to reflect the ongoing changes in society where the low/high culture distinction (e.g. Bourdieu 1984) does not longer apply and takes into account the proliferation of new media.

Working definitions of "cultural participation" usually include visits to cultural attractions and sites (e.g. museums or archeological parks), attendance at events (e.g. going out 
to a movie or to a concert) as well as informal cultural actions such as participating in community cultural activities and amateur artistic productions, everyday activities like reading a book and listening to music (AEGIS 2004) and, since more recently, using the Internet for cultural purposes (European Commission 2012; Morrone 2006).

The present research refers to cultural participation as "Participation in Cultural Life" and defines it as:

The receptive and creative conscious activities through which people increase their informational and cultural baggage as far as four different cultural domains are concerned: Cultural Heritage, Performing Arts, Books and Press, Audio and Audiovisual Media and Multimedia.

Various theoretical considerations have inspired this definition. With respect to the concept of culture, a broad and anthropological approach that includes "not only art and literature, but lifestyles, ways of living together, value systems, traditions and beliefs" (UNESCO 2001), which is well consolidated in both the international policy discourse (UN Committee on Economic, Social and Cultural Rights 2009) and in the scholarly debate (Throsby 1995; Williams 1976), needs to be complemented with a rigorous operationalization to function as "a workable framework for cultural policies" (Romainville 2015, 413). Hence, following the most influential works in the field of Cultural Statistics that deal with empirical measurements (European Commission 2012; UNESCO 2009), the present paper delimits the scope of participation in cultural life using the construct of the "cultural domains" and including four of them, namely: Cultural Heritage, Performing Arts, Books and Press, Audio and Audiovisual Media and Multimedia. These four domains not only are all covered in ISTAT AVQ Survey (2014), but are also considered to reflect the increasingly varied landscape of cultural participation. They in fact allow us to encompass both the more "traditional" forms of cultural participation that usually regard the Cultural Heritage and Performing Arts domains, but also other types of leisure activities and daily forms of cultural consumption, that normally "happen" in the Books and Press, Audio and Audiovisual Media and Multimedia domains. According to recent research conducted in the UK, this second type of involvement represents the most significant part of people's cultural participation, even for those who have a low interest in State-supported culture (Taylor 2016).

For what concerns the types and patterns of behaviour to be included, previous works agree on the fact that participation in cultural life should be considered as a "conscious act" (European Commission 2000, 2012; Morrone 2006; UNESCO 2009), including the multiple forms and settings through which the individual actively seeks to increase her/his informational and cultural baggage. What distinguishes participation in cultural life from other unintentional forms of cultural consumption, e.g. passing by a monument while window shopping or bumping into a cultural content on the web, are the elements of willingness and awareness through which people actively try to learn a code of communication for having access to a wide range of cognitive, aesthetic, spiritual, physical, political, emotional and social values (on this point see Brown 2004). To take part in cultural life implies a set of decisions and involves a complex mix of attitudes, intentions, constraints and behaviours as well as feedback between that mix and past experiences (McCarthy and Jinnett 2001).

In the light of this consideration and trying to move forward from the intuitive, but hard to define, distinction between active and passive participation, different taxonomies have been proposed in order to grasp the multi-faceted behaviours through which people interact with the cultural realm. The Leadership Group Culture (LEG), for instance, analysed cultural participation distinguishing between "attending/receiving", "performance/production" and "interaction process" (European Commission 2000). The Australian Expert 
Group in Industry Studies (AEGIS 2004) classified cultural participation into "receptive", such as going to a concert, and "creative", such as the active learning of a musical instrument. More recently, the European Statistical System Network on Culture (ESSnet-Culture) introduced the so-called ICET model, where cultural participation is unpacked in four dimensions: "Information", "Communication and Community", "Enjoyment and Expression" and "Transaction" (European Commission 2012).

The present definition of "Participation in Cultural Life" adopts the receptive and creative participation approach proposed by AEGIS, which actually mirrors some of the elements underlined by both the LEG's and the ESSnet-Culture's classifications. Receptive participation thus includes the acts of receiving, purchasing, attending, observing or seeking information about a cultural product or expression belonging to one of the four cultural domains considered. This dimension reflects the "attending/receiving" part of the definition proposed by the LEG and the "information" and "enjoyment" concepts of the ICET model, where the individual is considered as the "receiving subject" of the cultural message and the focus is on its interpretation and enjoyment. Creative participation instead indicates the active engagement of people in making, creating, organizing, initiating, producing and facilitating cultural and creative activities. Coherently with the "performance/production" dimension of the LEG's definition and with the "communication" and "expression" concepts employed in the ICET model, the focus is on the individual as "creator" and "communicator" of material and immaterial cultural contents, either for an audience or for a private pleasure, either in organized or in not organized context, but without professional aims. The creative dimension of the definition includes also cultural activities realized through digital means and online platforms. Cultural participation has in fact profoundly changed, also in the light of the growing use and diffusion of information and communication technologies. Therefore, "merely measuring physically attending canonised cultural institutions [would] miss[es] an increasing part of the picture" (European Commission 2012, 410). It should be noted, however, that although we propose distinguishing between receptive and creative types of cultural participation, in "real life", the two concepts may well overlap. For instance, innovative theatre performances or exhibitions may actively engage the audiences as co-creators. Moreover, it is also useful for the purposes of the present analysis to underline that both dimensions of "Participation in Cultural Life" include time intensive aspects: both "receptive" and "creative" behaviours imply the use of considerable and "exclusive" amount of time by individuals. Cultural participation is, in this sense, highly affected by time constraints (Willekens and Lievens 2016).

\subsection{Participation in Civic Life}

Participation in civic life generally refers to the numerous ways through which the individual interacts with the broader community and the social context where she/he lives. As such, it has been analysed by several disciplines (Political Science, Sociology, Community Psychology) that have focused their attention on similar concepts like "sense of community" (McMillan and Chavis 1986), "social participation" (Cicognani et al. 2008), "active citizenship" (Hoskins 2006), "citizen participation" (Oser 2017) and "civic engagement" (Doolittle and Faul 2013). Many have attempted to operationalise and measure this concept for conducting both cross-country comparisons and quantitative analyses at micro level. Keeter et al. (2002) have developed the Index of Civic and Political Engagement, Doolittle 
and Faul (2013) have proposed the Civic Engagement Scale, Talò and Mannarini (2015) and Hoskins and Mascherini (2009) the Active Citizenship Composite Indicator.

Building again on these previous works and data available, the present research defines "Participation in Civic Life" as:

The behaviours and attitudes through which people express their willingness of interacting within the community and contributing to its well-being, as far as four dimensions are concerned: Political life, Civil society, Community life and Civic sense.

The proposed conceptualisation is grounded in several theoretical assumptions derived from the literature. Regarding the participation patterns, it is assumed that the willingness that people need and use for being involved in the community level could be expressed by both behaviours and attitudes (Doolittle and Faul 2013). While civic behaviours are the actions that people take to actively attempt to engage and make a difference in their social context, civic attitudes are the personal beliefs and feelings that people have about their involvement and their perceived ability to produce a social change. This component has also been defined as "latent" or "invisible" participation (Talò and Mannarini 2015).

As far as the realm of civic life is concerned, it takes inspiration from the value-based connotation of "civic community" defined by Putnam et al. (1993). Therefore, participation in civic life is characterised by the awareness that collaboration can create value "that no individual [...] could produce alone" and based on "a conception of one's role and obligations as a citizen" (183).

In terms of typology of behaviours and attitudes, the proposed definition tries to capture and classify the breadth of activities that individuals could undertake for being involved in public life, assuring, at the same time, proper data coverage within the Italian system. Reinterpreting previous taxonomies (Ekman and Amnå 2012; Hoskins and Mascherini 2009; Keeter et al. 2002), four dimensions of participation in civic life have been individuated: Political Life, Civil Society, Community Life and Civic Sense. This distinction reflects the necessity of looking beyond the "classical" electoral or political party-related participation. It has the purpose of broadening the concept by including diverse "non-conventional" behaviours-petitioning, protesting, internet activism, political consumerismthrough which people can express their civic engagement (Copeland 2014; Micheletti and McFarland 2011).

The "Political life" dimension has been articulated in two sub-dimensions: "political activity" and "interest in politics". "Political activity" refers to those activities that are available to the people within the model of representative democracy (Ekman and Amnå 2012). It includes all the actions undertaken in relation to the party membership, the participation in party meetings, the donation of money to parties and the support given to them through volunteering. "Interest in politics" measures the "attentiveness" of people, namely people's involvement in political events through the attention they pay to them (Keeter et al. 2002).

The "Civil Society" dimension refers to the "action by ordinary citizens directed towards influencing some political outcomes" (Brady 1999, 737, quoted in Talò and Mannarini $2015,800)$. It includes the activities that people generally engage with to give expression to their political and social viewpoint and make their voice heard by the public institutions, both in the form of protests, strikes and boycotts and through the active engagement in civil society organizations that promote government accountability and positive social change (Hoskins and Mascherini 2009). The type of organisations usually considered for identifying this type of participation are human rights or environmental organisations and trade unions. 
The dimension that deals with the "Community Life" refers to voluntary activities focused on addressing local community's problems and providing help and resources to the non-profit sector. Instead of being promoted for producing social change and expressing political opinions as in the "Civil Society" dimension, this type of participation originates mainly from a sense of solidarity with others and an orientation towards the common good (Hoskins and Mascherini 2009; Keeter et al. 2002). Active collaborations with religious, business, sport, cultural and social organizations are considered participatory behaviours of this kind.

The "Civic sense" dimension has been introduced in order to complete the analysis of the participation in civic life with an enlarged conception of participatory behaviours and attitudes. It embraces two sub-dimensions: "civic responsibility" and "trust in institutions". The "civic responsibility" grasps a mix of daily actions linked with the respect of the environment and the critical consumerism (getting informed about the food products; ecofriendly attitudes in the use of cars and water, etc.). As it has been underlined by Micheletti and McFarland (2011), everyday routines and personal lifestyles should be seen as new participatory behaviours through which people try to influence the socio-political context, making civic engagement an integral part of their life. "Trust in institutions" reflects the degree of confidence that people have towards the different levels of government (European and national parliaments, Regional and municipal councils etc.), the political parties, the judicial system and the police. Trust is considered a crucial component for describing and understanding people's ways of participating in civic life. Thus, the level of trust has proven to be an explanatory factor of people's engagement in non-institutional participation (Kaase 1999) or a fundamental driver for activating forms of collaboration with others (Ansell and Gash 2007).

Still, while both behaviors and attitudes are substantially relevant for the concept that we intend to measure, they affect individuals' allocation of time in a very different way. What we define as "behaviors"-mostly found under the above defined concepts of Political Life, Civil Society, and Community Life-cover activities such as participation in voting, volunteering or membership in civic organisations which usually entail an intensive commitment of time. Time is instead not relevant for the attitudes, values and beliefs composing the Civic Sense dimension. This aspect needs to be properly taken into account when analysing the relation between Cultural Participation and Civic Engagement as most (but not all) of the underlying activities compete for their own share of individuals' daily time. We therefore need to test whether the relation between the two exists and remains statistically significant if using time-use variables only.

\section{Data Source, Selection and Treatment}

Since both cultural participation and civic engagement are conceptualised as being integral part of the daily actions and lifestyles of people, the source of data used to build the two related indicators and measure their relation was the "Aspetti della Vita Quotidiana" (AVQ) Survey (2014), conducted on an annual basis by the Italian National Institute of Statistics (ISTAT). This survey aims at collecting information on different aspects of everyday life in Italy and includes a broad range of thematic areas, such as education, work, family and social life, free time, political and social participation, health conditions and use of public services. Its main goal is to measure both objective behaviours and actions and subjective perceptions, motivations and opinions in order to make social information 
about the Italians' daily life as complete as possible. With a view to be representative of the whole Italian population, the AVQ Survey involves a sample of more than 18,000 families (about 45 thousands persons), living in 850 municipalities of different demographic size. The use of data from 2014 is due to the unique availability of specific variables, which are fundamental in the definition of the two latent constructs of participation in cultural life (PCULT) and participation in civic life (PCIVIC).

Tables 1 and 2 present the list of variables selected to measure the two latent constructs of participation in cultural life (PCULT) and participation in civic life (PCIVIC) in line with the definitions formulated above. They also distinguish between what we call "timeuse variables" (TUV) and "attitudes variables" (AV) - a distinction that will be taken into account when studying the relation between the two constructs in the next sub-section.

Data treatment included a number of adjustments in order to facilitate the construction of the composite indicators and the interpretation of results. As a first step, all individuals aged less than or equal to 14 years have been excluded since neither their expressions of cultural participation nor their forms of civic engagement are necessarily to be intended as manifestations of a "conscious act". Furthermore, some aspects of participation are legally impossible for individuals younger than 14. In a second step, when necessary, the values of some variables have been reordered to make each highest value representative of the maximum realisation of the considered variable, or have been rearranged into classes. For instance, the reading habits have been measured through a single variable, having the following values: "0" when no book has been read in the last year, "1" when 6 or less books have been read in the last year; " 2 " when 7 up to 12 books have been read in the last year; " 3 " when 13 up to 52 books have been read (from one per month to one per week) and " 4 " when more than one book has been read each week. Furthermore, the two variables that measure the use of Internet for cultural activities in the last year and the ones that measure the use of Internet for political activity in the last year have been reclassified as having three possible values: "none of the two"; "one of the two"; "both of them". Also, for some variables response scales have been recorded in a 0-3 range (e.g. "everyday"; "sometimes per week"; "sometimes per month"; "rarely or never" for the variables related to the frequency of getting informed about politics and of talking about it, and "not at all"; "little"; "enough"; "a lot" for the trust in the institutions variables). Finally, the annual subscription to sport organisations variable has been merged with two other variables on expenditure for practising sport. The new variable assumes value " 0 " in case of no payment for practising sport in the last 12 months and " 1 " in case of payment done for at least one of three options available ("payment of an annual subscription to sport organisations"; "payment for private lessons of sport activities"; "practising sport in paid places"). All the variables based on a scale $0-10$ have been rearranged in three classes: "low" from 0 to 5, "enough" from 6 to 7 and "high" from 8 to 10.

\section{The Construction of the Composite Indicators Through the Poset Approach}

In order to measure complex multidimensional concepts such as the participation in cultural or civic life, it can be beneficial to synthesise the information provided by different and potentially relevant variables in two composite indicators (OECD-JRC 2008). The concept and definition of composite indicators, however, also presents disadvantanges and risks, especially when dealing with phenomena which cannot be easily quantified, such as 


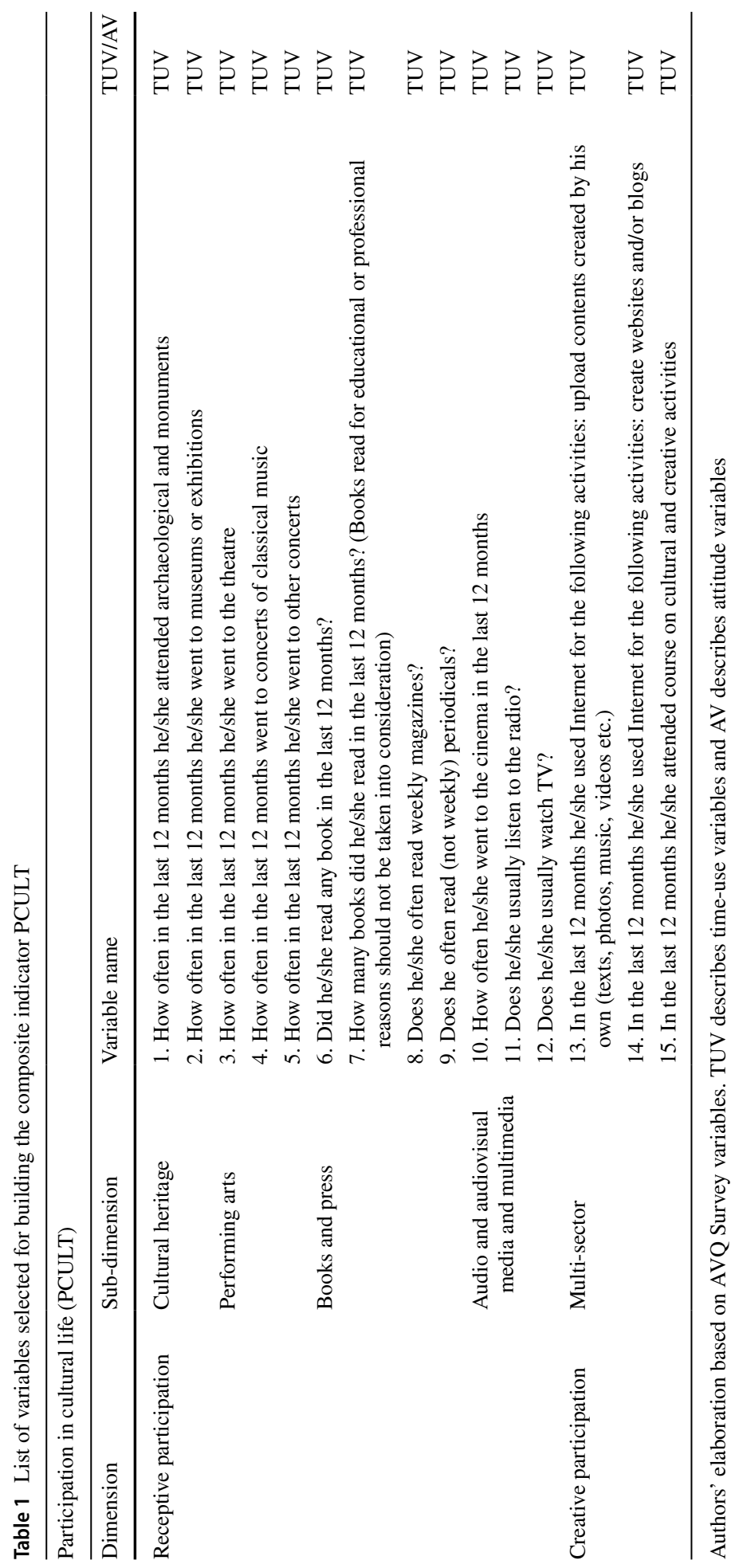




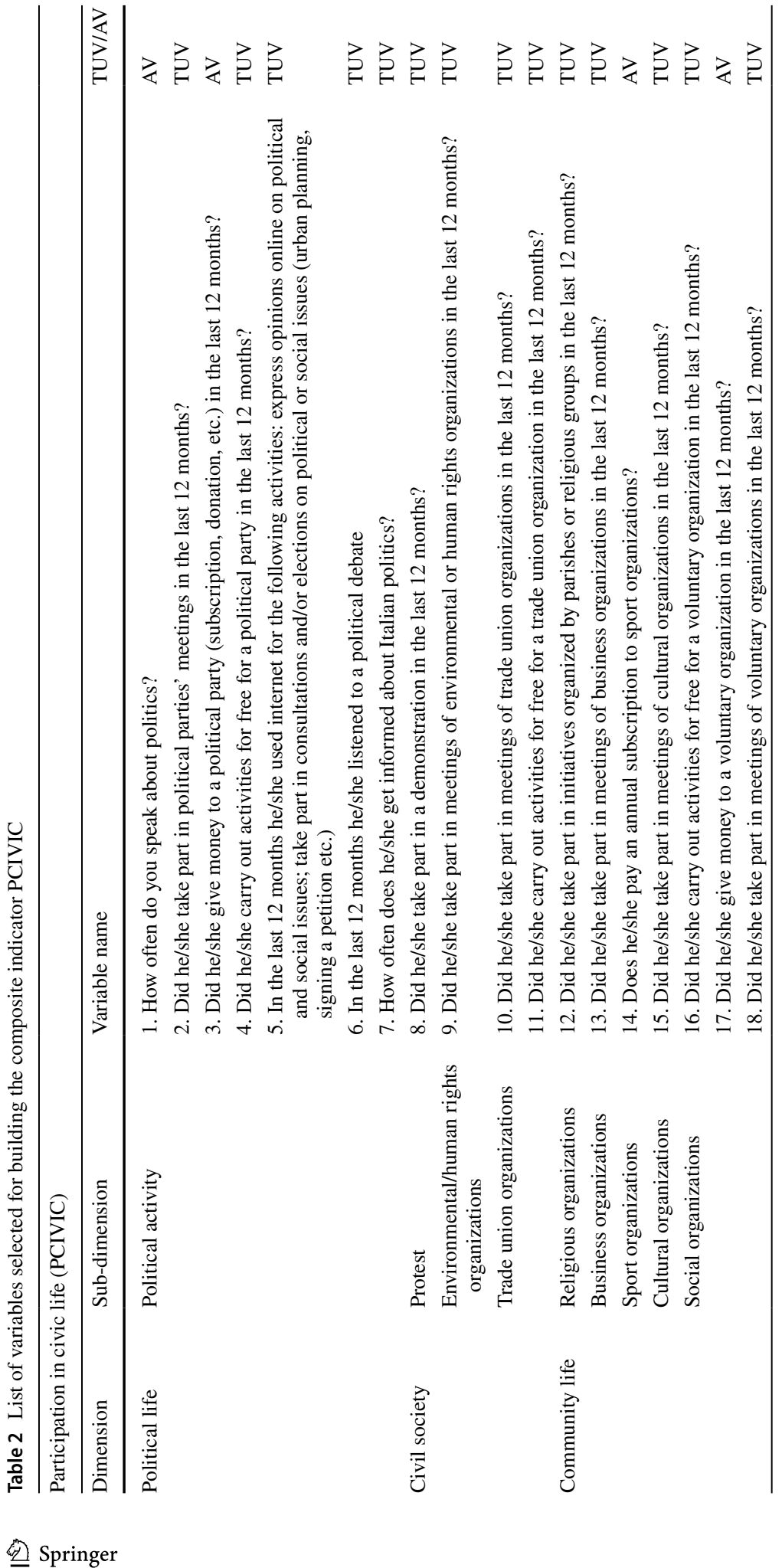




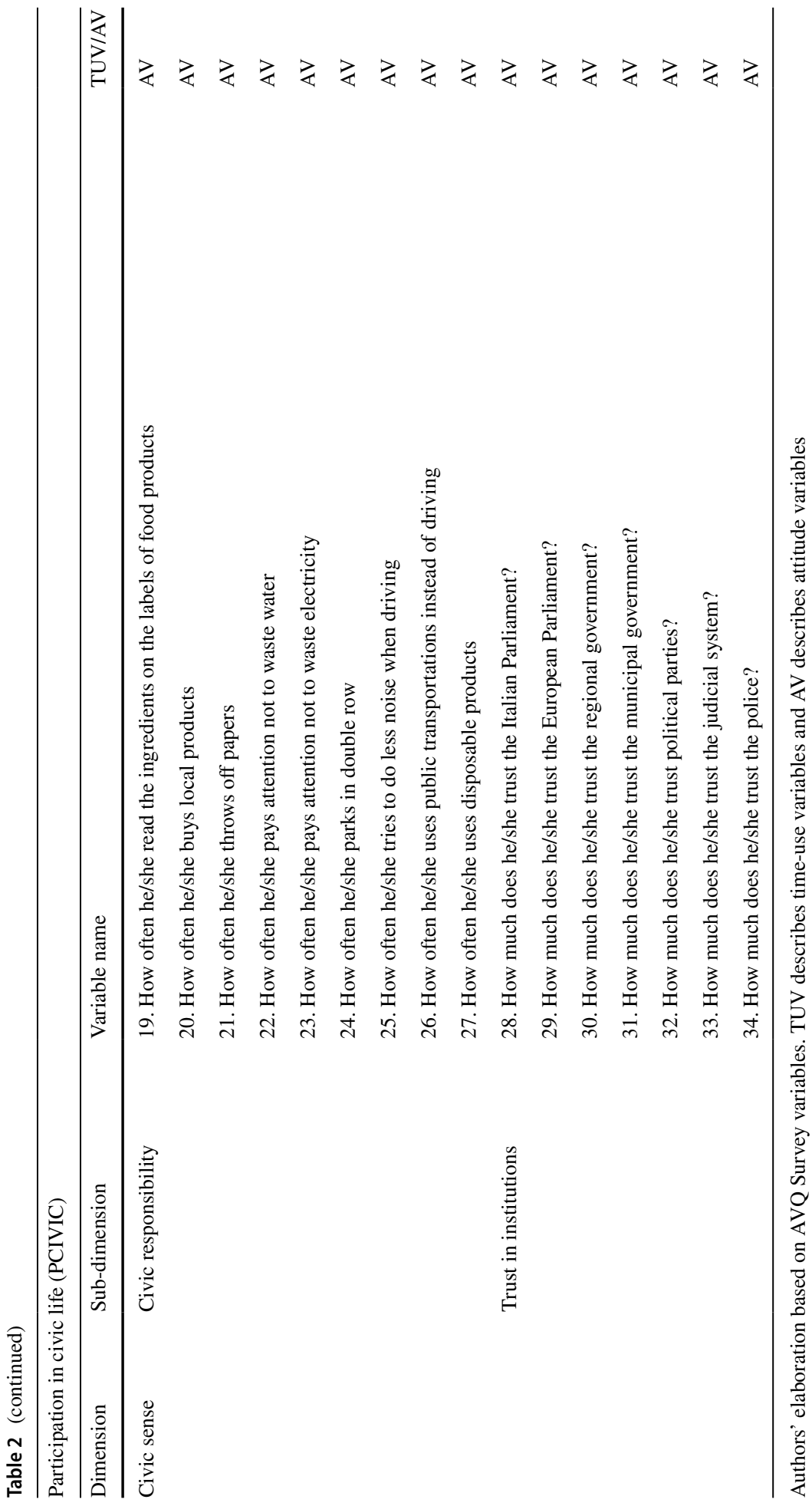


the ones that we wish to study in this paper. Synthesis, inevitably, reduces information and often uses subjective opinions open to criticisms.

The weighted arithmetic mean is the easiest and more intuitive way to create a composite indicator. An undesirable feature of additive aggregations, though, is the full compensability that they imply. Also, these aggregations are not necessarily appropriate for variables of ordinal type.

In recent years, scholars have tried to identify alternative ways to develop composite indicators, for instance using the so-called "ranking methods", which require the definition of an order among the observed units. When dealing with a group of many individuals, it is possible to rank them using a single criterion. For instance, the age or the education level is sufficient to determine who has the highest level in a pair of individuals. However, when it comes to the comparison of individuals using a system of different criteria, two elements may be neither equal nor ordered. When two individuals are not comparable, they are considered incomparable (Davey and Priestley 2002). When a complete order is impossible because of incomparabilities, we obtain a so-called "partial order". A set containing partially ordered elements is a Partially Ordered Set (poset).

An example can be observed in Table 3, where an individual answers two questions (called $q_{1}$ and $q_{2}$ ) about the quality of three objects $(x, y, z)$. In the comparison between $x$ and $y$, it is impossible to define which object is the best because of the conflict between the two criteria. This conflict determines an incomparability and implies the absence of an order between the elements $x, y$. The same situation happens between $x$ and $z$ but not between $y$ and $z$ where $y \geq z$ on every attribute. The set of values observed for every unit can be called profile of the unit. For instance, the profile of unit $x$ is (low, high). In the poset approach, every unit is defined by its entire profile.

As the measurement of participation in cultural and civic life implies the comparison of individuals in relation to multiple variables of ordinal type, we have opted for the poset approach and the connected Average Rank (AR) method in the construction of the composite indicators PCULT and PCIVIC. The procedure called AR is an intuitive approach to build a single synthetic measure out of a poset. The AR of an element of the poset is the mean of the ranks of that element among all the possible orders that can be obtained from a poset, respecting the observed relations of comparability between the different units (Brüggemann and Patil 2011). The computation of the AR results in a unique value describing the multidimensional concept that we want to measure using a set of elementary variables.

As a starting point, all the variables that are part of the same sub-dimension (e.g. Political Activities and Trust in Institutions) have been included in the computation of the specific sub-dimension, obtaining 16 sub-dimensions showing a single value for every subject. Then, the same process has been followed to compute the dimensions (e.g. Civic Sense and Receptive Participation) out of their constituting sub-dimensions. In the same way, the final indicators are obtained from the poset of their relative dimensions, except for PCULT which is computed out of dimension Creative Participation and the four sub-dimensions of

Table 3 Incomparability example

\begin{tabular}{lll}
\hline & $q_{1}$ & $q_{2}$ \\
\hline $\mathrm{x}$ & Low & High \\
$\mathrm{y}$ & Medium & Medium \\
$\mathrm{z}$ & Medium & Low \\
\hline
\end{tabular}


Receptive Participation to avoid an excess of importance of the creative dimension alone. The results of these steps were always rounded to the first decimal place to decrease the complexity of the comparison. In this work, every poset (sub-dimension, dimension and final measures) is defined out of the observed profiles. So, if some profile is not observed in the sample (e.g. high frequency of speaking about politics and minimum frequency of information about national politics), it is also not included in the poset and in the computation of the Average Rank. The dimension of every poset of dimensions and indicators is presented in Table 7 (Appendix 1), together with the proportion of possible profiles that are not observed in each of them.

The use of many variables in the definition of a poset may determine an increase in the number of incomparable elements. It is implicit when a poset is defined as the product order of the constituting variables. But, when a poset is constructed only on the observed profiles, as in this case, the proportion of incomparabilities may not change. The proportion of incomparabilities in the posets has been included in Table 7 (Appendix 1) in order to describe the structure of the posets. In addition, the proportion of incomparabilities has been weighted with the frequency of the relative profiles, the results are listed in Table 7 (Appendix 1).

The presence of incomparable couples of units is crucial in the computation of composite indicators by means of the average rank. For instance, there may be observations with a very high rank in a variable such as the frequency of speaking about politics and a very low rank in another such as the frequency of getting informed about politics; the opposite is also possible, and frequent, so two completely different subjects (High speaking politics-Low information and Low speaking-High information) will be present in the same poset, the poset of political activity in this case. If this kind of opposite cases appears and these share the same values on all the other variables, the AR formula will compute more or less the same results for both the non-similar observations. This is due to their similar average rank, given the absence of a priority measure defining the importance of the variables. Nevertheless, in the AR, the presence of a single extreme value in a profile can largely increase the incomparability of the unit. For instance, when a profile is severely unbalanced (best performance in a variable, worst in another), it is likely to be incomparable with most of the other profiles observed in the poset. Hence, the AR associated to this profile would never be extremely high (or low), but intermediate. This characteristic, strictly connected with the concept of non-compensatory aggregation, constitutes the main difference between the AR poset approach and the classic aggregation formulas.

All the ARs have been computed using the approximation formula of the average rank proposed by Brüggemann and Carlsen (2011) and the software R version 3.5.1 with the function proposed in Caperna (2016) which is based on the PARSEC package (Arcagni and Fattore 2014). While the meaning of the classic aggregation formulas is commonly intuitive, the results of the AR are not so straightforward. In particular, it is complicated to understand the relation between the presence of incomparabilities and the AR. We suggest to refer to Brüggemann and Patil (2011) for an extensive understanding of these aspects.

To facilitate readability and interpretation of results, the PCULT and PCIVIC's scores have then been normalized on an intuitive range of $0-100$, where 0 indicates the lowest level and 100 the maximum level of PCULT and PCIVIC respectively. In the analysis of the association between PCULT and PCIVIC, we have computed a multiple linear regression model (OLS) as a first step. Realizing the unfitting structure of data to the assumptions of linear regression, we have estimated a multiple quantile regression analysis (Koenker 2005) as already proposed for the analysis of Life Satisfaction based on poset indicators in Boccuzzo and Caperna (2017), where the synthetic indicator has been computed on 

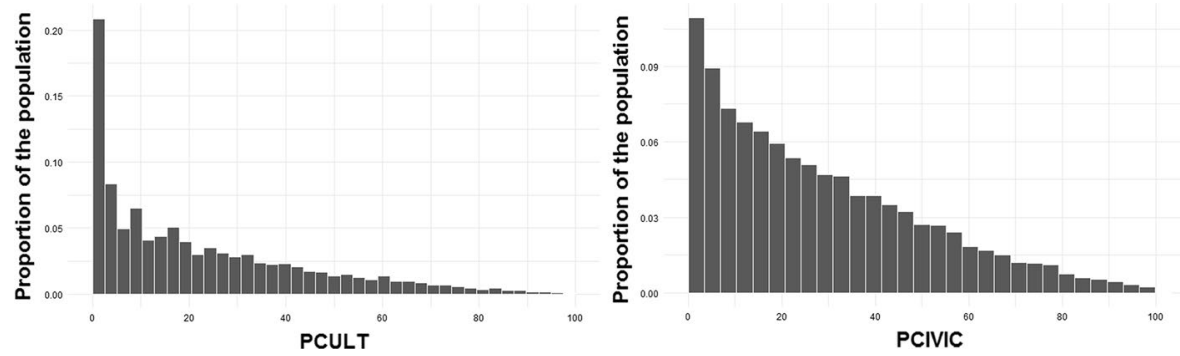

Fig. 1 Frequency distribution of the participation in cultural life (PCULT) and participation in civic life (PCIVIC) indicators among the Italian population. Source: Author's elaboration on ISTAT AVQ Survey (2014)

Table 4 Descriptive statistics of the participation in cultural life (PCULT) and participation in civic life (PCIVIC) indicators

\begin{tabular}{lcccccc}
\hline Variable & Min & 1st Q & Median & Mean & 3rd Q & Max \\
\hline PCULT & 0.00 & 3.88 & 15.74 & 22.02 & 34.03 & 100.00 \\
PCIVIC & 0.00 & 9.52 & 23.33 & 28.48 & 43.06 & 100.00 \\
\hline
\end{tabular}

the basis of the method proposed by Fattore (2016). In a most recent work from Fattore and Arcagni (2019), the authors have proposed an innovative approach to compare populations or meaningful sub-groups, comparing the frequency distributions of the observations among all the possible elements of the poset. On a different perspective, in this work the aim is to estimate the magnitude and direction of the association between PCULT and PCIVIC taking into account the influence of many socio-demographic variables, namely gender, age band, educational qualification, adequacy of the economic resources in the family, occupational situation, geographical partition and dimension of the municipality.

\section{Results}

Figure 1 shows the frequency distribution of the PCULT and PCIVIC indicators. The minimal level of cultural participation is undoubtedly the most frequent occurrence in the Italian population, with almost $30 \%$ of the respondents having a PCULT value lower than 5. Indeed, the mean and the median of the PCULT indicator are particularly low (22.02 and 15.74, respectively), as shown in Table 4. The number of individuals with a value of PCULT slightly higher than the centre of range (50) collapses to around $13 \%$. Overall, this graph suggests a low level of cultural participation among the Italian population, with only $4 \%$ of individuals showing a PCULT value higher than 70 .

As regards the PCIVIC indicator on the right-hand of Fig. 1, similarly shows that the lowest levels of civic engagement are the most frequent ones among the Italian population. On the other hand, the percentage of individuals with the lowest PCIVIC values is smaller (only 14\% show less than 5) compared to PCULT, determining the smoother shape of the histogram. Both of the indicators therefore share the same asymmetry, but PCIVIC shows a less steep distribution. Coherently with what we have just observed, the mean and the median of the PCIVIC are 28.48 and 23.33 respectively. 


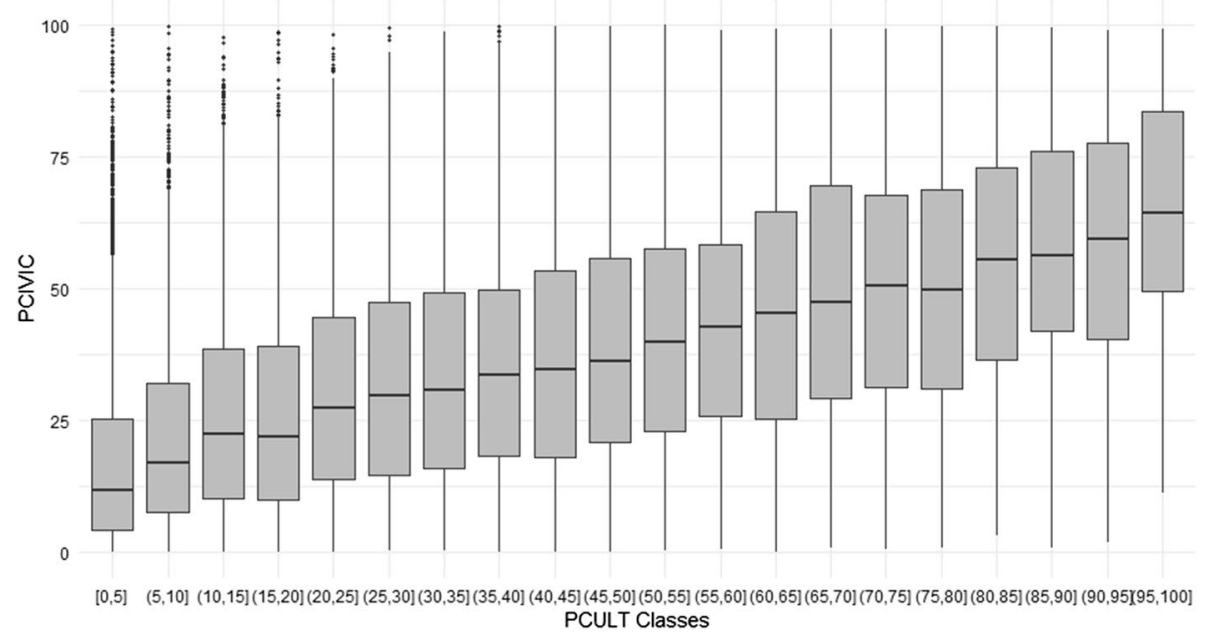

Fig. 2 Boxplots of PCIVIC for different classes of PCULT. Notes: On the horizontal axis, the PCULT indicator has been divided into classes of dimension 5, while on the vertical direction, the box plots of PCIVIC have been drawn relatively to the PCULT classes. Every grey box represents the first quartile, median and third quartile of the distribution for PCIVIC. So, for example, when the PCULT value is between 0 and 5 (first box on the left), the median of PCIVIC is 12.5, while the first and third quartiles are respectively close to 5 and 25

Table 5 Pearson's correlation coefficient and $\mathrm{R}^{2}$ for the PCULT and PCIVIC indicators. Source: Author's elaboration on ISTAT AVQ Survey (2014)

\begin{tabular}{lcc}
\hline Measure & Value & $p$ value \\
\hline Pearson's r & 0.462 & $<0.001$ \\
Spearman's rho & 0.454 & $<0.001$ \\
\hline
\end{tabular}

The relation between the two indicators has been investigated using different approaches. First, through the boxplots in Fig. 2, it is possible to appreciate the association between the two indicators, as higher levels of PCULT's classes correspond to higher levels of PCIVIC in the majority of the observations. Nevertheless, this association is not deterministic: some individuals have indeed a high PCIVIC value despite the low PCULT value. These individuals are represented by black dots on the highest value of PCIVIC for low classes of PCULT. Conversely, there are no individuals with the maximum level of PCULT and the minimum level of PCIVIC.

As a second step of the analysis, the value of the Pearson's and Spearman's correlations reported in Table 5 confirm the existence of a relatively high and statistically significant association. The similarity between the two correlation measures is probably motivated by the construction of the two indicators; the poset method is in fact based on mean of ranks, so the results of the Pearson's correlation are similar to the Spearman's one.

Although these coefficients do not imply any causal relation, they confirm that a highly statistically significant connection between the two constructs exists.

However, not only this association can go in both directions (PCULT $\rightarrow$ PCIVIC or PCIVIC $\rightarrow$ PCULT) but may also be affected by many other socio-economic variables. 
In this vein, we performed quantile regression analysis, with PCIVIC as response variable, PCULT and the socio-economic variables as explanatory variables (descriptive statistics of the explanatory variables are represented in Table 8, Appendix 2).

In addition, all possible interactions between PCULT and the socio-economic variables included in the model have been tested with a view to assess the "specific" effect of cultural participation on specific population clusters. For instance, in different age groups or in different educational qualifications, considering that individuals with different socioeconomic characteristics have very different preferences as well as sets of time use as regards both cultural participation and civic engagement, as well documented in the literature (e.g. Ateca-Amestoy et al. 2017; Nieminen et al. 2008). The final model has been estimated excluding the interactions of PCULT with the variables socio-economic resources and occupation which prove to generate a null improvement of the model.

The approach of analysis used here, called quantile regression (QR), is a type of regression analysis such as linear regression. The fundamental difference between QR and classic OLS linear regressions consist of the object of the estimation. The least squares method aims at estimating the conditional mean of the response variable, PCIVIC in our case, given the specific values of the predictor variables, PCULT and socio-demographics. Instead, quantile regression aims at estimating either the conditional median or other quantiles of the response variable. It can be interpreted as an extension of linear regression, and it is used here because the conditions of linear regression are not applicable. In particular, in this work, the estimation is computed for response variables representing first quartile, median and third quartile (respectively represented by tau $=0.25,0.5$ and 0.75 ).

The results of this model are represented in Table 6. Every column named by a value of tau identifies one of the three levels of estimation performed. For instance, when tau $=0.5$ the estimation is focused on the median of PCIVIC, and the listed values represent the effect of every level of the explanatory variable on the median of PCIVIC. Each of the estimated effects is equipped with a quantity from one to three asterisks according to the statistical $p$ value obtained $(* p<0.05, * * p<0.01, * * * p<0.001)$, and with the value of the specific $t$-statistics between brackets. In the first column of the same table, it is possible to find the description of the specific variable used as explanatory variable with all its levels. The estimates of the effects are always relative to some reference value. For instance, in the column with tau $=0.25$, we can see that being a woman, respect to be a man, determines a decrease of the expected response variable by an amount of 1.659. The interpretation is a little different when the explanatory variable is a PCULT or when we estimate the effect of the interaction between PCULT and something else (PCULT*). In such cases, the estimated value has to be read as the increase of PCIVIC that we could expect when PCULT increases by one.

The presence of attitudes variables (AV) in the construction of PCIVIC together with time-use variables (TUV) represents a possible source of distortion in the analysis of its relation with PCULT, and in the interpretations of PCIVIC itself. Despite the description of time use given in the survey is always based on qualitative levels such as "sometimes" or "often", it would be dangerous to ignore that TUVs are conflicting on the same scarce resource of time, while the AVs represent different sets of opinion where no explicit conflict could be assumed.

In order to check for the presence of this distortion and in the absence of variables giving us the amount of time allocated to the different activities considered, two additional quantile regressions have then been run: the first examines the relation between PCULT and PCIVIC maintaining only the TUVs of PCIVIC; the second one studies the association between PCULT and the Civic Sense construct, thus keeping only the main AV. All the other control variables are kept unchanged in the regression models. 
Table 6 Quantile regression on the effect of participation in cultural life (PCULT) and socio-economic variables on participation in civic life (PCIVIC)

\begin{tabular}{|c|c|c|c|}
\hline & $\mathrm{tau}=0.25$ & $\operatorname{tau}=0.50$ & $\mathrm{tau}=0.75$ \\
\hline Intercept & $9.149 * * *(4.73)$ & $21.631 * * *(12.06)$ & $42.528 * * *(12.92)$ \\
\hline PCULT (1 point) & $0.308 * * *(10.63)$ & $0.354 * * *(9.76)$ & $0.365 * * *(8.84)$ \\
\hline \multicolumn{4}{|l|}{ Age (24 or less) } \\
\hline $25-39$ & $3.373 * * *(9.6)$ & $5.09 * * *(7.41)$ & $6.694 * * *(5.96)$ \\
\hline $40-59$ & $5.499 * * *(15.19)$ & $9.716^{* * *}(14)$ & $14.503 * * *(13.13)$ \\
\hline $60+$ & $6.295 * * *(15.69)$ & $11.4 * * *(14.46)$ & $16.818 * * *(13.54)$ \\
\hline PCULT *25-39 & $0.009(0.49)$ & $0.02(0.76)$ & $-0.008(-0.24)$ \\
\hline PCULT *40-59 & $0.134 * * *(7.47)$ & $0.118 * * *(4.51)$ & $0.044(1.48)$ \\
\hline PCULT *60+ & $0.195 * * *(9.48)$ & $0.166 * * *(5.92)$ & $0.049(1.58)$ \\
\hline \multicolumn{4}{|l|}{ Gender (man) } \\
\hline Woman & $-1.659 * * *(-7.83)$ & $-3.799 * * *(-9.78)$ & $-5.836 * * *(-10.03)$ \\
\hline PCULT * woman & $-0.085^{* * *}(-6.32)$ & $-0.045^{* *}(-3.04)$ & $0.016(0.89)$ \\
\hline \multicolumn{4}{|c|}{ Highest qualification (Uni. degree) } \\
\hline High school & $-3.43 * * *(-4.24)$ & $-6.35 * * *(-6.05)$ & $-9.258 * * *(-7.93)$ \\
\hline Middle school & $-5.338 * * *(-6.73)$ & $-10.947 * * *(-10.53)$ & $-14.576^{* * *}(-12.48)$ \\
\hline Primary school & $-6.835 * * *(-8.61)$ & $-14.33 * * *(-13.27)$ & $-21.29 * * *(-16.77)$ \\
\hline No school title & $-8.134 * * *(-10.16)$ & $-17.757 * * *(-16.05)$ & $-28.792 * * *(-21.22)$ \\
\hline PCULT * high school & $-0.023(-1.06)$ & $0.015(0.63)$ & $0.064 *(2.35)$ \\
\hline PCULT $*$ middle school & $-0.086^{* * * *}(-3.51)$ & $0.026(0.99)$ & $0.057(1.89)$ \\
\hline PCULT * primary school & $-0.113 * * *(-3.53)$ & $0.015(0.35)$ & $0.199 * * *(5.09)$ \\
\hline PCULT * no school title & $-0.07 *(-2.1)$ & $0.111(1.94)$ & $0.283 * *(2.87)$ \\
\hline \multicolumn{4}{|c|}{ Socio-economic resources (excellent) } \\
\hline Adequate & $-2.030(-1.18)$ & $-3.197 *(-2.46)$ & $-9.068 * *(-3.16)$ \\
\hline Scarce & $-3.046(-1.76)$ & $-4.912 * * *(-3.77)$ & $-11.947 * * *(-4.15)$ \\
\hline Insufficient & $-3.633 *(-2.09)$ & $-5.322 * * *(-3.87)$ & $-12.752 * * *(-4.32)$ \\
\hline \multicolumn{4}{|l|}{ Occupation (employed) } \\
\hline Seek new one & $-0.834 * *(-2.64)$ & $-1.382 * *(-2.85)$ & $-0.759(-1.08)$ \\
\hline Seek first One & $-1.669 * * *(-4.79)$ & $-3.158 * * *(-4.46)$ & $-4.527 * * *(-4.46)$ \\
\hline House keeper & $-1.087 * * *(-3.90)$ & $-1.744 * * *(-3.68)$ & $-1.695^{*}(-2.43)$ \\
\hline Student & $2.342 * * *(5.77)$ & $3.929 * * *(5.52)$ & $5.48 * * *(5.20)$ \\
\hline Retired & $-0.384(-1.12)$ & $0.181(0.33)$ & $1.011(1.34)$ \\
\hline Other/unable & $-2.663 * * *(-8.91)$ & $-3.549 * * *(-4.85)$ & $-5.085 * * *(-4.86)$ \\
\hline \multicolumn{4}{|l|}{ Geo. partition (north-west) } \\
\hline North-east & $1.173 * *(2.91)$ & $1.589 *(2.53)$ & $2.048 *(2.10)$ \\
\hline Central & $0.034(0.09)$ & $0.74(1.29)$ & $-0.038(-0.05)$ \\
\hline South & $-0.99 * * *(-3.70)$ & $-2.089 * * *(-4.63)$ & $-3.198 * * *(-4.13)$ \\
\hline Main Isles & $-0.617(-1.86)$ & $-1.207 *(-2.01)$ & $-0.959(-1.00)$ \\
\hline Not available & $-2.161(-0.71)$ & $-2.994(-0.14)$ & $8.348(1.86)$ \\
\hline PCULT * north-east & $0.009(0.43)$ & $0(0)$ & $0.021(0.77)$ \\
\hline PCULT * central & $-0.004(-0.22)$ & $-0.056 * *(-2.66)$ & $-0.002(-0.07)$ \\
\hline PCULT* south & $0.009(0.47)$ & $0.021(0.9)$ & $0.052(1.95)$ \\
\hline PCULT $*$ main Isles & $0.069 * *(2.71)$ & $0.059 *(2.1)$ & $0.087 * *(2.59)$ \\
\hline PCULT $*$ not available & $0.017(0.05)$ & $0.178(0.23)$ & $-0.486(-0.56)$ \\
\hline
\end{tabular}


Table 6 (continued)

\begin{tabular}{lccc}
\hline \multicolumn{2}{c}{$\operatorname{tau}=0.25$} & tau $=0.50$ & tau $=0.75$ \\
\hline Municipality dimension (metropolitan area) & & \\
Less than 10,000 & $0.031(0.12)$ & $0.072(0.15)$ & $0.472(0.65)$ \\
More than 1000 & $0.087(0.37)$ & $-0.336(-0.75)$ & $-0.152(-0.22)$ \\
Not available & $-0.87(-1.27)$ & $-3.006(-1.94)$ & $-7.633^{*}(-2.22)$ \\
PCULT * less than 10,000 & $0.036 *(2.16)$ & $0.046 *(2.32)$ & $0.069 *(2.82)$ \\
PCULT * more than 10,000 & $0.024(1.57)$ & $0.053 *(3)$ & $0.05 *(2.33)$ \\
PCULT * not available & $0.031(0.16)$ & $0.107(0.81)$ & $0.273(1.74)$ \\
\hline
\end{tabular}

Estimated effects of the quantile regression are reported; $t$-statistics in parentheses. Response variable: PCIVIC. Explanatory variables: the reference levels are in parentheses. Legend of significance level: $* p<.05, * * p<.01, * * * p<.001$

In the rest of this sub-section, the results of the two additional models are shortly presented while the tables with the detailed results are given in Table 8 (Appendix 3).

Table 6 shows that PCULT has a positive and statistically significant association with PCIVIC: the 0.354 regression coefficient in the central column means that an increase of the PCULT indicator value by one is associated with, on average, an increase of 0.354 in the value of the median of PCIVIC, assuming that all the other variables in the model remain constant. In other words, cultural participation is significantly associated with civic engagement, even when controlling for potential confounding variables. This association is slightly stronger for higher values of PCULT, probably due to the cumulative effects of arts and cultural participation. As argued by McCarthy et al. (2004), cultural participation benefits build over time as the individual becomes more insightful and more skilled to engage in community life.

It is also worth noticing that although educational attainment is a very much influential predictor of civic engagement, cultural participation remains positively and significantly associated with civic participation even after controlling for education. In a way, two separate and certainly complementary effects are found - an aspect that is often overlooked when considering the association between cultural access levels, civic engagement and educational attainment. The results of the interaction effects are even more promising: while cultural participation is, in most cases, not significantly or negatively associated with civic engagement for more educated people (see interaction effects with High School and Middle School), the association is positive and highly significant for people that participate more in civic life (tau $=0.75$ ) but have no school or a primary school title. Therefore, we could assume that at lower levels of civic engagement, cultural participation has a sort of substitution effect for certain educational levels: the negative and statistically significant coefficient for the interactions PCULT* middle school $(-0.086)$ and PCULT* primary school $(-0.113)$ indeed show that an increase of the PCULT indicator value by one is associated with, on average, a decrease in the value of the first quartile of PCIVIC. In other words, individuals choose to focus either on cultural or civic participation activities. Conversely, at higher levels of civic participation, cultural participation seems to have an additive effect on civic engagement, which results to be particularly strong for people having no educational qualification: an increase of the PCULT indicator value by one is associated with, on average, a 0.283 increase in the value of the third quartile of PCIVIC for people with no school title. Taking this result from a different perspective, the subset of the population with low educational level can balance what it misses for a low education $(-21.29$ and -28.79$)$ with an intense participation in cultural life. Indeed, an increase of 100 points in PCULT means an increase of 19.9 and 28.3, 
respectively, for individuals who have finished primary school and for those who didn't have this opportunity.

The results also show that older people appear to be more engaged than the reference group (i.e. young people having between 14 and 24 years old). Moreover, the association of PCULT with PCIVIC is positive for people in the higher age ranges (40-59 and 60+), but only in the first and second quartile of PCIVIC. This means that cultural participation is not a discrimination criterion of civic engagement for individuals in different age groups for high levels of civic participation. Again, it is useful to look at the classes as populations groups, in order to values the implications of the interaction of PCULT with age; the 40-59 class shows a positive parameter of 9.71 with respect to the reference. But, if the interaction is taken into account, this class could gain even more than the basic parameter (up to 11.8 when PCULT reach its maximum of 100). The same is true for the highest class too.

As regards gender and the employment status, civic engagement is lower among women than among men and it decreases as cultural participation increases, while students engage significantly more than employed people. Their engagement increases at higher levels of PCIVIC. No significant difference is instead found between occupied and retired individuals. Also, as probably expected, civic engagement is lower for individuals seeking a job as well as for people with adequate, scarce or insufficient socio-economic resources compared to the reference level (i.e. excellent resources). However, civic engagement is not dependent on socio-economic resources for lower levels of civic engagement $(\operatorname{tau}=0.25)$.

Geographical partition has been investigated using North-West as the reference area, but it does not seem to be a highly significant discriminant of civic participation. However, it is possible to recognise the North-East as the most participative area (1.173) and the South as the least one $(-0.99)$. Particular attention is deserved to the municipality dimension: if this variable is considered alone in a model, the estimations show no effect on civic participation. Conversely, if the effect is controlled for the other socio-economic variables, municipalities with fewer inhabitants have a small but positive and statistically significant effect on PCIVIC (0.036, $0.046,0.069)$ in the three quartiles. Therefore, cultural participation may act as a vehicle of social inclusion in small communities through its positive association with civic engagement.

Our main relation of interest remains positive and statistically significant even after controlling for TUV (see Table 9, Appendix 3). One major difference can, however, be observed: when keeping only time-use variables, the relation is significantly positive at the three quantile levels of civic engagement (tau $=0.25,0.5$ and 0.75$)$ but the coefficients is practically halved at the first and second quartile level while is substantially the same at the third quartile level. The reduction of the parameter value is interesting, but it is mainly due to the general decrease in the value of PCIVIC when computed on TUVs. This reduction makes the result of quartile three central; at the high level of PCIVIC, the relation with PCULT has the same strength for the entire PCIVIC and the TUV subset. On the contrary, the model based on AVs returns a smaller value for the parameter of PCULT even at the third quartile, although the average value of PCIVIC based on AV is very close to the complete one. This is interesting as it supports the hypothesis that people that participate in arts are also the ones engaging more in society, despite the fact that time is a limited resource.

\section{Discussion and Conclusions}

Social inclusion is an important factor of European development and it is an objective of European policies. It has extensively been argued that participation in arts and cultural activities can contribute to processes of social inclusion and therefore to advance 
a more cohesive society. However, empirical evidence proving the relation between cultural participation and civic engagement is rather scarce.

The quantitative evidence provided in this paper supports the argument according to which participation in the arts and cultural activities is positively correlated with civic engagement. More precisely, cultural participation remains a significant predictor of an individual's engagement in civic life even after controlling for confounding sociodemographic variables (education, income, age and gender) and for time use. In other words, culture does contribute to make better citizens, and this positive effect is slightly stronger for people who are highly involved in a large variety of cultural activities. Our findings therefore suggest that arts and culture are more than leisure-time entertainment activities as they seem to contribute to the socio-cultural inclusion of individuals.

These results confirm what has been affirmed in previous studies maintaining that attending or practicing cultural activities can for instance improve individuals' interest in or understanding of civic issues, provide settings in which people can discuss, and take action or increase social capital and community capacity (Stern and Seifert 2009). These kinds of socio-cultural benefits are even more relevant nowadays as they can potentially reach audiences who are new to arts and culture. As Agovino et al. (2017) point out, while many types of cultural experiences may suffer from a stigmatised image, some other types, such as digitally mediated forms of cultural participation, are much more inclusive as they reach out also people who do not regularly access arts and culture. Cultural venues such as museums, heritage sites and art galleries but also cultural associations or cooperatives of artists are in fact increasingly adopting digital technologies or gamified approaches that help transmit to broader and "unusual" audiences new knowledge or context for civic action (Bergamo et al. 2014; Bria et al. 2015; Mortara et al. 2014).

A key policy implication of our findings and resulting reflections is that greater attention should be directed to introducing more citizens to arts and cultural experiences as a social inclusion vehicle. Such a demand-side policy approach would require that more resources are devoted toward cultivating demand. This approach is certainly not new. But the efficacy of policy measures aiming to stimulate participation in culture, especially among those who are not "regular participants", is to be questioned considering that education and income remain important predictors of cultural participation. A policy approach that promotes interdisciplinary dialogue and innovative cooperation could possibly be more effective in reaching broader audiences. At a higher strategic level, cultural and social policy-makers could for instance work more closely together with a view to support the "social dissemination" of culture for securing citizen engagement and social inclusion processes. At operational level, the development of strategic partnerships between civil society organisations, on the one hand, and innovative cultural and creative organisations, on the other, could help approach new audiences as well as strengthen the virtuous cycle that links cultural participation and civic life. Encouraging citizens to address socially-relevant issues is the more urgent nowadays that people seem progressively detached from their reference community and that the number of marginalised individuals, especially within cities and big metropoles, is increasing.

Although the findings confirm the association between cultural participation and civic engagement, a number of limitations must be noted. First, the use of cross sectional data prevents us from examining causal links. Secondly, the two phenomena of interest cannot be fully explained by arts participation and a few demographic variables, due to their intrinsic complexity. Other variables such as family background and early socialization might indeed affect one's cultural participation and civic engagement. In fact, while civic engagement is an individual variable, the cause and the effects of the derived actions are linked to higher 
levels of aggregation (e.g. family). Therefore, "looking for direct and immediate links between arts and civic engagement is likely to underestimate their relationship" (Stern and Seifert 2009). Finally, quantitative analysis is not sufficient to understand how cultural participation works to produce the social outcomes of interest. While a number of explanations have been advanced to explain the link between arts participation and civic engagement, causal mechanisms remain obscure. Qualitative mixed methods of analysis may help better understand and interpret the quantitative results that we have obtained.

Despite the limitations, our analysis adds confirmatory evidence to the previous studies that establish the relationship between cultural participation and individual-level engagement in society. More importantly, it takes research in the area a step further by empirically proving the existence of a virtuous circle between cultural and civic engagement in a European country, while existing empirical research on the topic mostly covers the US. It also provides a more relevant methodological approach (poset) to capture the multidimensional nature of the concepts under investigation and their relationship. In addition to the main variables of interest, several background variables were indeed included in the regression model in order to account for their possible effects on the outcome variables. Although education-which is usually assumed and found to be a very important predictor of civic engagement-is confirmed to be a statistically significant determinant of participation in civic life, cultural participation remains a significant, and certainly complementary, predictor. In addition to that, it is particularly interesting and promising to notice that cultural participation has a positive effect on civic engagement for people engaging more in civic life but having a low educational level. Culture may therefore be instrumental in fostering civic inclusion, regardless of the educational level of individuals, and help counter social segregation deriving from educational gaps. In line with the expectations, we also found that the availability of socio-economic resources is statistically significant in predicting civic engagement, although the economic situation seems to account more for individuals who engage more. Ultimately, this analysis highlights the potential of arts participation for promoting active citizenship. The findings are encouraging but more research is needed to allow for the generalization of our results beyond the Italian case under study. Availability of relevant data at European level would be crucial to extend the analysis to more countries and hopefully help the European Union advance its ongoing reflection on the future of its social dimension. Future research could also more specifically look at the "unique" social benefits of cultural participation compared to other kinds of activities such as sports practice, or study the effect of culture on civic life at regional or neighborhood level and assess whether richer and more accessible cultural offers contribute to higher level of cultural participation and civic engagement, even for individuals with lower educational or income levels.

Open Access This article is licensed under a Creative Commons Attribution 4.0 International License, which permits use, sharing, adaptation, distribution and reproduction in any medium or format, as long as you give appropriate credit to the original author(s) and the source, provide a link to the Creative Commons licence, and indicate if changes were made. The images or other third party material in this article are included in the article's Creative Commons licence, unless indicated otherwise in a credit line to the material. If material is not included in the article's Creative Commons licence and your intended use is not permitted by statutory regulation or exceeds the permitted use, you will need to obtain permission directly from the copyright holder. To view a copy of this licence, visit http://creativecommons.org/licenses/by/4.0/.

\section{Appendix 1}


Table 7 Descriptive statistics on the posets of sub-dimensions, dimensions, and PCULT and PCIVIC constructs

\begin{tabular}{llllll}
\hline Level & Name & $\begin{array}{l}\text { \# Observed } \\
\text { elements }\end{array}$ & $\begin{array}{l}\text { \% Unob- } \\
\text { served } \\
\text { profiles }\end{array}$ & $\begin{array}{l}\text { \% Incompa- } \\
\text { rable profiles }\end{array}$ & $\begin{array}{l}\text { Weighted } \% \text { of } \\
\text { incomparable } \\
\text { profiles }\end{array}$ \\
\hline Dimension & Receptive participation & 2296 & 0 & 72.69 & 39.58 \\
Dimension & Creative participation & 9 & 0 & 22.2 & 0.38 \\
Indicator & PCULT & 3924 & 0 & 80.41 & 43.92 \\
\hline Level & Name & \# Observed & $\%$ Unob- & $\%$ Incompa- & Weighted \% of \\
& & elements & served & rable profiles & $\begin{array}{l}\text { incomparable } \\
\text { profiles }\end{array}$ \\
\hline Dimension & Political life & & profiles & & po.37 \\
Dimension & Civil society & 390 & 91.54 & 71.79 & 0.56 \\
Dimension & Community life & 21 & 56.25 & 40.36 & 12.30 \\
Sub-dimension & Civic responsibility & 1137 & 80.66 & 84.22 & 57.52 \\
& Trust in institutions & 1065 & 51.30 & 82.07 & 25.65 \\
Dimension & Civic sense & 2835 & 0 & 45.60 & 40.86 \\
Indicator & PCIVIC & 8402 & 0 & 73.88 & 52.18 \\
\hline
\end{tabular}

The table contains the number of elements observed in the poset (unique profiles), the percentage of possible profiles that are not observed in the data, proportion of incomparabilities, proportion of incomparabilities weighted for the frequency of the incomparable profiles

\section{Appendix 2}


Table 8 Descriptive statistics of the explanatory variables used in the quantile regression
Variable

Percentage (\%)

Age

24 or less

12.23

25-39

21.53

40-59

35.32

$60+$

30.92

Gender

Man

48.18

Woman

51.82

Highest qualification

University degree

13.01

High school

Middle school

Primary school

15.94

No school title

Socio-economic resources

Excellent

Adequate

52.85

Scarce

39.25

Insufficient

7.08

Occupation

Employed

Seek new one

9.35

Seek first one

2.66

House keeper

14.42

Student

8.32

Retired

20.21

Other/unable

Geo. partition

North-west

26.54

North-east

18.89

Central

20.01

South

23.33

Main Isles

11.15

Not available

0.08

Municipality dimension

Metropolitan area

27.09

Less than 10,000

29.11

More than 1000

43.31

Not available
0.49

\section{Appendix 3}




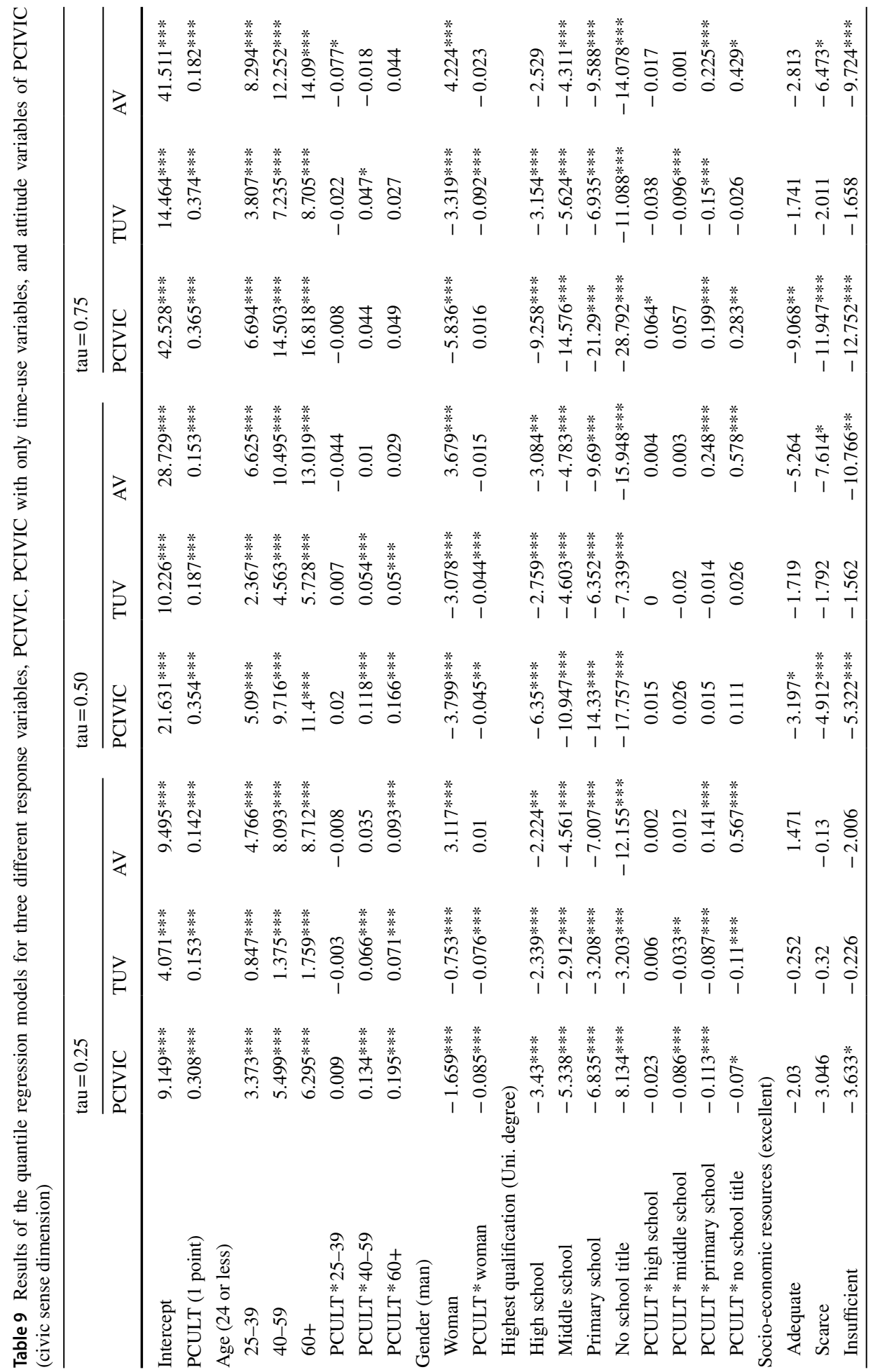




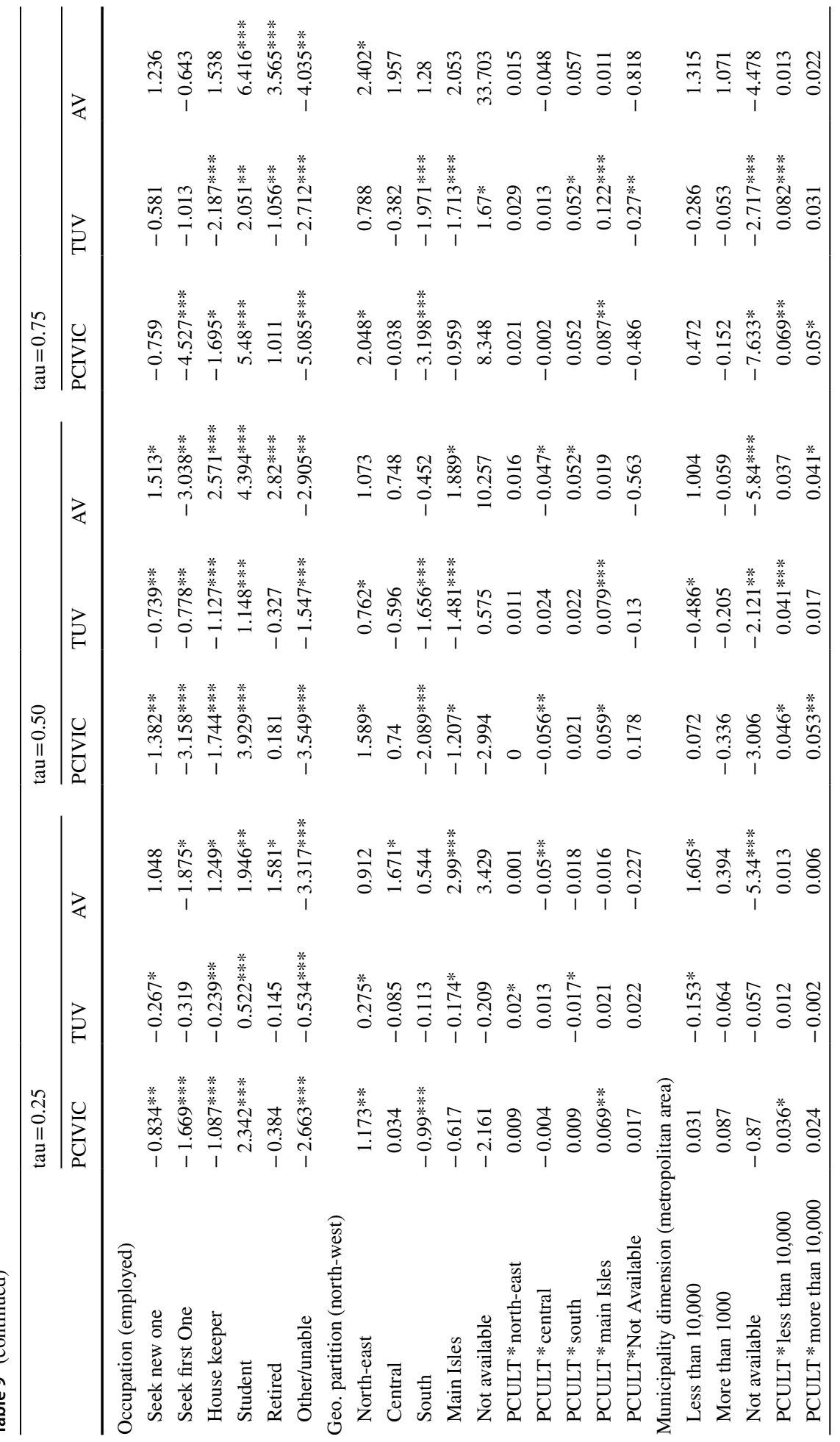




$$
\Gamma
$$




\section{References}

AEGIS. (2004). Social impacts of participation in the arts and cultural activities-Stage two report. Retrieved January 27, 2020 from https://www.stategrowth.tas.gov.au/_data/assets/pdf_ file/0003/160833/Social_Impacts_of_the_Arts.pdf.

Agovino, M., Crociata, A., Quaglione, D., Sacco, P., \& Sarra, A. (2017). Good taste tastes good. Cultural capital as a determinant of organic food purchase by italian consumers: Evidence and policy implications. Ecological Economics, 141, 66-75. https://doi.org/10.1016/j.ecolecon.2017.05.029.

Ansell, C., \& Gash, A. (2007). Collaborative governance in theory and practice. Journal of Public Administration Research and Theory, 18(4), 543-571. https://doi.org/10.1093/jopart/mum032.

Arcagni, A., \& Fattore, M. (2014). PARSEC: An R package for poset-based evaluation of multidimensional poverty. In R. Bruggemann, L. Carlsen, \& J. Wittmann (Eds.), Multi-indicator systems and modelling in partial order. Berlin: Springer.

Ateca-Amestoy, V. M., Ginsburgh, V., Mazza, I., O’Hagan, J., \& Prieto-Rodriguez, J. (Eds.). (2017). Enhancing participation in the arts in the EU. Cham: Springer International Publishing. https://doi. org/10.1007/978-3-319-09096-2.

Atkinson, T., Cantillon, B., Marlier, E., \& Nolan, B. (2002). Social indicators. Oxford: Oxford University Press. https://doi.org/10.1093/0199253498.001.0001.

Belfiore, E. (2006). Evaluating value. Arts Professional, 115, 10-11. Retrieved from https://www.artsprofes sional.co.uk/magazine/article/sounding-board-evaluating-\%18value\%19.

Bergamo, L., Donahue, K., Klimpel, P., Levä, K., Negri, M., Pagel, J., ... Zipsane, H. (2014). Museums in the digital age museums and the development of active citizenship. NEMO 21st annual conference documentation. Retrieved January 27, 2020 from http://www.ne-mo.org/fileadmin/Dateien/public/state ments_and_news/NEMO_21st_Annual_Conference_Documentation.pdf.

Boccuzzo, G., \& Caperna, G. (2017). Evaluation of life satisfaction in Italy: proposal of a synthetic measure based on poset theory. In Complexity in society: From indicators construction to their synthesis (pp. 291-321). Cham: Springer.

Bourdieu, P. (1984). Distinction: A social critique of the judgement of taste. Harvard: Harvard University Press.

Bria, F., Gascó, M., Baeck, P., Halpin, H., Almirall, E., \& Kresin, F. (2015). Growing a digital social innovation ecosystem for Europe-DSI final report. Retrieved January 27, 2020 from https://www.nesta .org.uk/sites/default/files/dsireport.pdf.

Brown, A. (2004). The values study: Rediscovering the meaning and value of arts participation. Retrieved January 27, 2020 from https://www.giarts.org/sites/default/files/values-study-rediscovering-the-meani ng-and-value-of-arts-participation.pdf.

Brüggemann, R., \& Carlsen, L. (2011). An improved estimation of averaged ranks of partial orders. MATCH Communications in Mathematical and in Computer Chemistry, 65, 383-414.

Brüggemann, R., \& Patil, G. P. (2011). Ranking and prioritization for multi-indicator systems: Introduction to partial order applications. Springer Science \& Business Media.

Caperna, G. (2016). Partial order theory for synthetic indicators. Padova: University of Padova.

Catterall, J. S., Dumais, S. A., \& Hampden-Thompson, G. (2012). the arts and achievement in at-risk youth: Findings from four longitudinal studies. Retrieved January 27, 2020 from https:/www.arts.gov/sites/ default/files/Arts-At-Risk-Youth.pdf.

Cicognani, E., Pirini, C., Keyes, C., Joshanloo, M., Rostami, R., \& Nosratabadi, M. (2008). Social participation, sense of community and social well being: A study on American, Italian and Iranian University Students. Social Indicators Research, 89(1), 97-112. https://doi.org/10.1007/s11205-007-9222-3.

Copeland, L. (2014). Conceptualizing political consumerism: How citizenship norms differentiate boycotting from buycotting. Political Studies, 62(1_suppl), 172-186. https://doi.org/10.1111/14679248.12067.

Council of the European Union. (2010). Conclusions on the role of culture in combating poverty and social exclusion. Retrieved January 27, 2020 from http://www.consilium.europa.eu/Newsroom.

Davey, B. A., \& Priestley, H. A. (2002). Introduction to lattices and order. Cambridge University Press.

Delaney, L., \& Keaney, E. (2006). Cultural participation and social capital in the United Kingdom: Statistical evidence from national and international survey data. Retrieved January 27, 2020 from https:// www.ippr.org/files/uploadedFiles/research/projects/Democracy/cultural participation social capital etc. pdf?noredirect $=1$.

Doolittle, A., \& Faul, A. C. (2013). Civic engagement scale: A validation study. SAGE Open, 3(3), 215824401349554. https://doi.org/10.1177/2158244013495542.

Ekman, J., \& Amnå, E. (2012). Political participation and civic engagement: Towards a new typology. Human Affairs, 22(3), 283-300. https://doi.org/10.2478/s13374-012-0024-1. 
European Commission. (2000). Cultural statistics in the EU-Final report of the LEG 3/2000 N. 1. Retrieved January 27, 2020 from https://publications.europa.eu/en/publication-detail/-/publicatio n/4d8189d2-5dae-4ce7-87c7-d932932ed965/language-en.

European Commission. (2007). Communication on a European agenda for culture in a globalising world$\operatorname{COM(2007)} 242$ final. Retrieved January 27, 2020 from http://eur-lex.europa.eu/legal-content/EN/ TXT/?uri=LEGISSUM\%3A129019.

European Commission. (2012). ESSnet culture final report. Retrieved January 27, 2020 from https:// ec.europa.eu/eurostat/cros/content/essnet-culture-final-report_en.

European Commission. (2013). Communication on strengthening the social dimension of the economic and monetary union-COM/2013/0690 final. Retrieved January 27, 2020 from http://eur-lex.europa.eu/ legal-content/EN/TXT/?uri=celex\%3A52013DC0690.

European Commission. (2017a). Communication on strengthening European identity through education and culture-COM(2017) 673 final. Retrieved January 27, 2020 from https://ec.europa.eu/commission/ sites/beta-political/files/communication-strengthening-european-identity-education-culture_en.pdf.

European Commission. (2017b). Reflection paper on the social dimension of Europe. Retrieved January 27, 2020 from https://ec.europa.eu/commission/sites/beta-political/files/reflection-paper-social-dimensioneurope_en.pdf.

European Commission. (2018). The new European agenda for culture. European Commission. Retrieved January 27, 2020 from https://ec.europa.eu/info/law/better-regulation/initiatives/ares-2018-15227 68_en.

European Commission and Council of the European Union. (2004). Joint report by the Commission and the Council on social inclusion-7101/04. Retrieved January 27, 2020 from http://ec.europa.eu/emplo yment_social/soc-prot/soc-incl/final_joint_inclusion_report_2003_en.pdf.

European Parliament. (2002). Resolution on the importance and dynamics of the theatre and the performing arts in an enlarged Europe-A5-0264/2002. Retrieved January 27, 2020 from http://www.europarl.europa.eu/sides/getDoc.do?pubRef=-//EP//TEXT+REPOR $\mathrm{T}+\mathrm{A} 5-2002-0264+0+\mathrm{DOC}+\mathrm{XML}+\mathrm{V} 0 / / \mathrm{EN}$.

European Parliament. (2007). Resolution on social reality stocktaking-A6-0400/2007. Retrieved January 27, 2020 from http://www.europarl.europa.eu/sides/getDoc.do?type=REPORT\&reference=A62007-0400\&language $=$ EN.

Fattore, M. (2016). Partially ordered sets and the measurement of multidimensional ordinal deprivation. Social Indicators Research, 128, 835-838. https://doi.org/10.1007/s11205-015-1059-6.

Fattore, M., \& Arcagni, A. (2019). F-FOD: Fuzzy first order dominance analysis and populations ranking over ordinal multi-indicator systems. Social Indicators Research, 144(1), 1-29. https://doi. org/10.1007/s11205-018-2049-2.

Hill, K. (2008). Social effects of culture. Statistical Insights on the Arts, 6(4). Retrieved from http:// www.hillstrategies.com.

Hoskins, B. (2006). Draft framework for indicators on active citizenship. Retrieved January 27, 2020 from http://citeseerx.ist.psu.edu/viewdoc/download?doi=10.1.1.132.1723\&rep=rep1\&type=pdf.

Hoskins, B., \& Mascherini, M. (2009). measuring active citizenship through the development of a composite indicator. Social Indicators Research, 90(3), 459-488. https://doi.org/10.1007/s1120 5-008-9271-2.

ISTAT. (2014). Indagine multiscopo sulle famiglie: Aspetti della vita quotidiana. Retrieved January 27, 2020 from https://www.istat.it/it/archivio/91926.

Jeannotte, M. S. (2003). Singing alone? The contribution of cultural capital to social cohesion and sustainable communities. International Journal of Cultural Policy, 9(1), 35-49. https://doi. org/10.1080/1028663032000089507.

Jeannotte, M. S. (2017). The social effects of culture-A literature review. Retrieved January 27, 2020 from https://socialsciences.uottawa.ca/governance/sites/socialsciences.uottawa.ca.governance/files/ social_effects_of_culture-final.pdf.

Kaase, M. (1999). Interpersonal trust, political trust and non-institutionalised political participation in Western Europe. West European Politics, 22(3), 1-21. https://doi.org/10.1080/014023899084253 13.

Keeter, S., Zukin, C., Andolina, M., \& Jenkins, K. (2002). The civic and political health of the nation: A generational portrait. Retrieved January 27, 2020 from https://eric.ed.gov/?id=ED498892.

Koenker, R. (2005). Quantile regression. New York: Cambridge University Press.

Kononykhina, O., Leong Cohen, J., Haber, M., Berneaud-Kötz, M., Kaufmann, S., Mejia, L., et al. (2016). Cultural participation and inclusive societies. Retrieved January 27, 2020 from https:// rm.coe.int/cultural-participation-and-inclusive-societies-a-thematic-report-based/1680711283. 
Leroux, K., \& Bernadska, A. (2014). Impact of the arts on individual contributions to US civil society. Journal of Civil Society, 10(2), 144-164. https://doi.org/10.1080/17448689.2014.912479.

Matarasso, F. (1997). Use or ornament? Comedia. https://doi.org/10.1258/ce.2009.009009.

McCarthy, K. F., \& Jinnett, K. J. (2001). A new framework for building participation in the arts. Santa Monica: Rand Corporation.

McCarthy, K. F., Ondaatje, E. H., Zakaras, L., \& Brooks, A. (2004). Gifts of the muse-Reframing the debate about the benefits of the arts. Retrieved January 27, 2020 from https://www.rand.org/conte nt/dam/rand/pubs/monographs/2005/RAND_MG218.pdf.

McMillan, D. W., \& Chavis, D. M. (1986). Sense of community: A definition and theory. Journal of Community Psychology, 14(1), 6-23. https://doi.org/10.1002/1520-6629(198601)14:1\%3c6:AIDJCOP2290140103\%3e3.0.CO;2-I.

Merli, P. (2002). Evaluating the social impact of participation in arts. International Journal of Cultural Policy, 8(1), 107-118. Retrieved from http://www.variant.org.uk/19texts/socinc19.html.

Micheletti, M., \& McFarland, A. S. (2011). Creative participation: Responsibility-taking in the political world. Boulder: Paradigm Publishers.

Morrone, A. (2006). Guidelines for measuring cultural participation. Retrieved January 27, 2020 from http://uis.unesco.org/sites/default/files/documents/guidelines-for-measuring-cultural-participation2006-en.pdf.

Mortara, M., Catalano, C. E., Bellotti, F., Fiucci, G., Houry-Panchetti, M., \& Petridis, P. (2014). Learning cultural heritage by serious games. Journal of Cultural Heritage, 15(3), 318-325.

National Endowment for the Arts (NEA). (2009). Art-goers in their communities: Patterns of civic and social engagement. Retrieved January 27, 2020 from https:/www.arts.gov/sites/default/files/98.pdf.

Nieminen, T., Martelin, T., Koskinen, S., Simpura, J., Alanen, E., Härkänen, T., et al. (2008). Measurement and socio-demographic variation of social capital in a large population-based survey. Social Indicators Research, 85(3), 405-423. https://doi.org/10.1007/s11205-007-9102-x.

OECD-JRC. (2008). Handbook on constructing composite indicators: Methodology and user guide. Paris: OECD.

Oser, J. (2017). Assessing how participators combine acts in their "political tool kits": A person-centered measurement approach for analyzing citizen participation. Social Indicators Research, 133(1), 235258. https://doi.org/10.1007/s11205-016-1364-8.

Polzella, D. J., \& Forbis, J. S. (2016). Relationships between different types and modes of arts-related experiences, motivation, and civic engagement. Washington. Retrieved January 27, 2020 from https://www. arts.gov/sites/default/files/Research-Art-Works-Dayton3.pdf.

Putnam, R. D., Leonardi, R., \& Nanetti, R. (1993). Making democracy work: Civic traditions in modern Italy. Princeton University Press. Retrieved January 27, 2020 from https://books.google.it/books/about /Making_Democracy_Work.html?id=gKZP8_Tp27UC\&redir_esc=y.

Romainville, C. (2015). Defining the right to participate in cultural life as a human right. Netherlands Quarterly of Human Rights, 33(4), 405-436. https://doi.org/10.1177/016934411503300404.

Selwood, S. (2002). Measuring culture. Retrieved January 27, 2020 from http://www.spiked-online.com/ newsite/article/6851\#.WszB1X-nIU.

Stern, M. J., \& Seifert, S. C. (2009). Civic engagement and the arts: Issues of conceptualization and measurement. Retrieved January 27, 2020 from https://animatingdemocracy.org/sites/default/files/CE_Arts_ SternSeifert.pdf.

Talò, C., \& Mannarini, T. (2015). Measuring participation: Development and validation the participatory behaviors scale. Social Indicators Research, 123(3), 799-816. https://doi.org/10.1007/s1120 5-014-0761-0.

Taylor, M. (2016). Nonparticipation or different styles of participation? Alternative interpretations from taking part. Cultural Trends, 25(3), 169-181. https://doi.org/10.1080/09548963.2016.1204051.

Throsby, D. (1995). Culture, economics and sustainability. Journal of Cultural Economics, 19, 199-206. https://doi.org/10.2307/41810549.

UN Committee on Economic Social and Cultural Rights. (2009). Right of everyone to take part in cultural life. Retrieved January 27, 2020 from http://www.refworld.org/docid/4ed35bae2.html.

UNESCO. (2001). UNESCO universal declaration on cultural diversity. Retrieved January 27, 2020 from http://unesdoc.unesco.org/images/0012/001271/127162e.pdf.

UNESCO. (2009). 2009 UNESCO framework for cultural statistics. Retrieved January 27, 2020 from http:// unesdoc.unesco.org/images/0019/001910/191061e.pdf.

Willekens, M., \& Lievens, J. (2016). Who participates and how much? Explaining non-attendance and the frequency of attending arts and heritage activities. Poetics, 56, 50-63. https://doi.org/10.1016/j.poeti c.2016.01.004. 
Williams, R. (1976). Keywords: A vocabulary of culture and society. Oxford University Press. Retrieved January 27, 2020 from https://books.google.it/books/about/Keywords.html?id=E4PnCwAAQB AJ\%26redir_esc $=\mathrm{y}$.

Publisher's Note Springer Nature remains neutral with regard to jurisdictional claims in published maps and institutional affiliations. 